\title{
Concept mapping strategy: An effective tool for improving maternity nursing students' achievement
}

\author{
Rania Eid Farrag* \\ Faculty of Nursing, Fayoum University, Fayoum, Egypt
}

Received: July 27, 2016

DOI: $10.5430 /$ jnep.v7n3p10
Accepted: August 24, $2016 \quad$ Online Published: October 18, 2016

URL: http://dx.doi.org/10.5430/jnep.v7n3p10

\begin{abstract}
Background: One of the duties of the educational system is to train nursing students to possess critical and creative thinking and have the ability of problem solving, those who do not accumulate information and knowledge regarding the maternity field that will be quickly outdated. As well, these criteria need to be provided in maternity nursing, to be able to achieve the mother and neonate safety. Concept map is one of the teaching strategies that can overcome this challenge. Aim of the study: To evaluate the effect of concept mapping strategy for improving maternity nursing students' achievement.

Methods: Design: A quasi-experimental study design was used to conduct the study. Setting: The study was conducted at the Maternity and Neonatal Health Nursing Department (third year students), in the Faculty of Nursing, Fayoum University. Subjects and Methods: A total of 125 students, all the students enrolled in the academic years 2014/2015. The students in the first term were the control group (65) and subjected to traditional method of teaching; and students in second term were the study group (60) subjected to concept map strategy. Tools used to collect the data were: 1) Sociodemographic characteristic: A structured interviewing questionnaire, 2) Pre/posttest to assess student's (study group) knowledge regarding concept mapping, 3) Student's achievement test (midterm \& final exam), 4) Rubric for assessing concept maps, and 5) Likert scale to assess the attitude of students toward the teaching strategy.

Results: There was a statistically significant difference regarding concept map knowledge pre and after awareness sessions among the study group. As well, there was a significant difference between both groups regarding the students' achievement (midterm \& final exam). In addition the students in the study group exhibit positive attitude regarding the teaching strategy (concept map) more than the students in the control group (traditional method).

Conclusions: Concept mapping significantly enhanced the students' achievement in the maternity nursing during the pregnancy course.
\end{abstract}

Key Words: Concept mapping, Students' achievement, Students' attitude

\section{INTRODUCTION}

Nowadays, nursing education aims not only to provide an appropriate level of knowledge and skill performance to nursing students but also is expected to improve problem solving, decision making, and critical thinking abilities in different situations. ${ }^{[1]}$ Information explosion resulting from the increased amount of available daily information that could be attributed to the advancement of sciences. Accordingly, nursing students need to actively receive the most recent information to face problems with the use of tools available by the newest technologies. Nursing students are becoming more eager learners, as the deeper and more long-lasting the knowledge they gain, the more effectively they can explain and apply it in reality, at hospitals, clinics and health

*Correspondence: Rania Eid Farrag; Email: farragrania@yahoo.com; Address: Faculty of Nursing, Fayoum University, Fayoum, Egypt. 
centers. ${ }^{[2]}$

Although, traditional method of education does teach the nursing students a certain amount of information, related to many specialties, it does not equip them with the tools that improve graduate nurses' critical thinking, to be able to analyze, prioritize, and organize new information required for effective learning. Therefore, it is great of importance that the roles of universities, change, especially in the medical and paramedical faculties as nurses of only a store of knowledge; and teachers just store of lecturers, transfer of knowledge and learning; instead of merely learning and memorizing, students should improve their thinking and inference skills and learn how to analyze information and use it whenever needed. ${ }^{[3]}$

Concept mapping (CM) is an active teaching strategy, under constructivism, placing the students at the centre of learning activity and the teacher as a facilitator which aims at fostering meaningful learning by students. ${ }^{[4]}$ Concept mapping is a modern educational strategy based on the Ausubel's learning assimilating theory. ${ }^{[5]}$ The theory reported that the meaningful learning occurs when newly learned materials can be linked to the information previously stored in the brain. Concept maps are explained and described in a hierarchical map structure with links to form valid propositions or linking words. ${ }^{[6]}$ General concepts are illustrated at the top of the map, and progressively more specific concepts are placed under one another to form a hierarchy. Major concepts are circled or boxed. Lines show relationships or links, and the direction of the thought process is indicated with arrows. Propositional links between concepts, showing the meaning of the relationship between the two concepts, are represented by connecting lines with words that describe the relationship written along the lines. ${ }^{[7]}$

Concept mapping uses a rich social environment as learning strategy, where learners work either individually or in groups to mediate learning of each other. Concept maps give the students an opportunity to: First: Think about the connections between the terms being learned; Second: In a systematic way, organize their thoughts and visualize the relationships between key concepts; and third: Reflect on their understanding. To summarize, concept maps allow students to think deeply. As well, students when discussing their maps with each other also articulate and challenge their thoughts about any new concept. Briefly, concept maps are excellent tools for a cooperative activity that will lead to very meaningful learning. ${ }^{[8]}$

To the develop cognitive domain among nursing students, concept mapping is one of the teaching strategies used, since the cognitive domain contains learning skills predominantly related to mental (thinking) processes. In addition, cognitive domain involves the acquisition of knowledge and learning processes which include a hierarchy of skills involving processing information, constructing understanding, applying knowledge, solving problems, and conducting research. ${ }^{[9]}$

Nurses play a major role in helping the pregnant woman and her partner. Pregnancy is a time of many physiologic and psychological changes that can positively or negatively affect the woman, her fetus and her family. Misconceptions, inadequate information, and unanswered questions about pregnancy, birth, and parenthood are common. ${ }^{[10]}$

To help nursing students to deal with the pregnant women efficiently based on scientific and organized knowledge, new educational strategies in nursing education as a concept map is used. The nurse as educator has several roles as trying to help pregnant women get the most accurate information, working to minimize the impact of health problems on her health, making sure that they are not inactive and isolated, but empowering them to be active agents in their health care plan. Nurse as educator has also the opportunity to meet the pregnant women in $\mathrm{MCH}$ centers, and discuss with each woman individually in order to provide her with information, knowledge or skills that she is in need to make her own appropriate choices and decisions for her health care plan. ${ }^{[11]}$

\subsection{Significance of the study}

Improving the quality of maternity nursing care and achieving the mother and neonate safety concept, where nurses can be invaluable in preventing harm to mothers and improving their pregnancy outcomes, all of that requires obtaining high levels of knowledge and skills during nursing academic period. The world today needs graduates who can take advantage of their diverse skills and in-depth academic knowledge in order to benefit from professional problem solving and long life learning. Hence, nurses encountering fast changes in the system of health care and education systems will realize that they are in a challenging and continually varying complex situations. Therefore, the teaching strategies should enable the learners to cope with these challenges. In line with this progress era, complexity and the rate of the nursing knowledge production is increasing steadily. Superficial learning and incomplete information have affected the performance of nursing students in dealing with the pregnant women and have led to women's complaints from inadequate knowledge of the nurses. Therefore, to prevent such problems, nursing educators should use new teaching methods that prevent superficial learning and lead to improvement of critical thinking skills, problem solving and increasing the students' memory. That will be reflected on the rank of the faculty among the other nursing faculties. Concept mapping 
is one of the active teaching methods that can help nursing educators to train graduates who are capable of critical thinking and problem solving. It is an activity that provides the student with an opportunity to organize, summarize, analyze and evaluate many different ideas. As well, to provide the teacher with information about student understandings. The theoretical framework of concept mapping teaching approach is based on meaningful learning. Learning occurs when the learner is able to organize and relate the concepts and new information with his/her cognitive mental structures. Learners underlying knowledge structures allow them to retrieve existing information and apply it to new learning and new tasks.

\subsection{Aim of the study}

The present study aims to evaluate the effect of concept mapping strategy for improving maternity nursing students achievement.

This aim was achieved through:

(1) Developing concept mapping as an educational material for maternity nursing (in the theoretical part of the pregnancy lectures; normal and abnormal) and testing its validity.

(2) Letting the student acquire the ability to design a concept map as student's feedback for understanding the lectures and the researcher applying a rubric system as an evaluation tool for a concept map based assignment for the study group.

(3) Comparing the achievement of the students subjected to traditional teaching method and students subjected to concept mapping through midterm and the final exam of maternity nursing.

(4) Identifying the students' attitude towards the teaching strategy.

\subsection{Research hypotheses}

- The concept map teaching method will improve the Maternity nursing students' achievement in the theoretical part of pregnancy lectures than the traditional method of teaching.

- Maternity nursing students who will be taught the pregnancy lectures by concept mapping will have a positive attitude toward the teaching strategy more than those who will be taught by traditional method.

\section{SUBJECTS AND METHOdS}

\subsection{Research design}

A quasi-experimental design was utilized in this study.

\subsection{Study setting}

The study was conducted at the Maternity and Neonatal Health Nursing Department (third year students) in the Faculty of Nursing, Fayoum University.

\subsection{Subjects}

All of nursing students (125) in Maternity and Neonatal Health Nursing Department, Faculty of Nursing, Fayoum University, enrolled in the academic year 2014/2015 were included. All nursing students, enrolled in the first term (65 students) and subjected to traditional educational method throughout pregnancy lectures made up the control group; while the study group included all of the nursing students enrolled in the second term (60 students), and those were subjected to concept mapping educational method throughout the theoretical part of pregnancy lectures. The teacher (the researcher) and the textbooks for both classes were the same to avoid confounding effects on the experiment.

\subsection{Tools of data collection}

For data collection five tools were used in this study:

(1) A structured interviewing questionnaire: Designed by the researcher, it was used to assess personal characteristics of students as: age, sex and previous educational certificate.

(2) Pre/posttest to assess students' (study group) knowledge regarding concept mapping: This tool was developed by the researcher after reviewing the relevant literature. It was used to assess the study groups' knowledge about concept mapping. It included twenty questions related to the concept map as definition of concept mapping, its goals, benefits, types, uses, components and steps for developing a concept map. The total test score was calculated from forty marks and the score of each student obtained from the total correct answers. Cronbach's $\alpha$ of this tool was 0.73 in this study.

(3) Student's achievement test (midterm and final written exam): Designed by the researcher and the supervisor of the department, it included questions regarding the theoretical part of pregnancy lectures (normal \& high risk) to assess the different levels of learning (cognitive levels) as knowledge, comprehension, application, analysis, synthesis and evaluation. It was used for both control and study groups. The student's achievement in the exam was scored according to the operational scoring system at the academic setting in Egypt as follows:

(1) Excellent: $85 \%-100 \%$

(2) Very good: $75 \%-85 \%$

(3) Good: $65 \%-<75 \%$

(4) Pass: $60 \%-<65 \%$ 
(5) Poor: $<60 \%$

(4) Rubric for assessing concept map: This rubric adopted, from McMurray, ${ }^{[12]}$ was used to evaluate the students' concept map to ensure their understanding for the lectures and organize the data of the lectures by themselves in their own concept map (CMs). Grading of these CMs was not calculated for the course evaluation, but was used to assess students' progress and effectiveness of using CMs (see Figure 1).

\begin{tabular}{|c|c|c|c|}
\hline CATEGORY & (3) & (2) & (1) \\
\hline $\begin{array}{l}\text { Arrangement of } \\
\text { Concepts }\end{array}$ & $\begin{array}{l}\text { Main concept easily identified; } \\
\text { sub-concepts branch appropriately } \\
\text { from main idea }\end{array}$ & $\begin{array}{l}\text { Main concept easily identified; } \\
\text { most sub-concepts branch from } \\
\text { main idea. }\end{array}$ & $\begin{array}{l}\text { Main concept not clearly identified; } \\
\text { sub-concepts don't consistently } \\
\text { branch from main idea. }\end{array}$ \\
\hline $\begin{array}{l}\text { Links and } \\
\text { Linking Lines }\end{array}$ & $\begin{array}{l}\text { Linking lines connect related } \\
\text { terms/point in correct direction; } \\
\text { linking words accurately describe } \\
\text { relationship between concepts; } \\
\text { hyperlinks effectively used }\end{array}$ & $\begin{array}{l}\text { Most linking lines connect } \\
\text { properly; most linking words } \\
\text { accurately describe the relationship } \\
\text { between concepts; most hyperlinks } \\
\text { effectively used. }\end{array}$ & $\begin{array}{l}\text { Linking lines not always pointing in } \\
\text { correct direction; linking words } \\
\text { don't clarify relationships between } \\
\text { concepts; hyperlinks don't function } \\
\text { or fail to enhance the topic. }\end{array}$ \\
\hline Graphics & $\begin{array}{l}\text { Graphics used appropriately; greatly } \\
\text { enhance the topic and aid in } \\
\text { comprehension; are clear, crisp and } \\
\text { well situated on the page. }\end{array}$ & $\begin{array}{l}\text { Graphics used appropriately most } \\
\text { of the time; most graphics selected } \\
\text { enhance the topic, are of good } \\
\text { quality, and are situated in logical } \\
\text { places on the page. }\end{array}$ & $\begin{array}{l}\text { Graphics used inappropriately and } \\
\text { excessively; graphics poorly } \\
\text { selected and don't enhance the } \\
\text { topic; some graphics are blurry and } \\
\text { ill-placed. }\end{array}$ \\
\hline Content & $\begin{array}{l}\text { Reflects essential information; is } \\
\text { logically arranged; concepts } \\
\text { succinctly presented; no misspellings } \\
\text { or grammatical errors }\end{array}$ & $\begin{array}{l}\text { Reflects most of the essential } \\
\text { information; is generally logically } \\
\text { arranged; concepts presented } \\
\text { without too many excess words; } \\
\text { fewer than three misspellings or } \\
\text { grammatical errors. }\end{array}$ & $\begin{array}{l}\text { Contains extraneous information; is } \\
\text { not logically arranged; contains } \\
\text { numerous spelling and grammatical } \\
\text { errors. }\end{array}$ \\
\hline Text & $\begin{array}{l}\text { Easy to read/ appropriately sized; no } \\
\text { more than three different fonts; } \\
\text { amount of text is appropriate for } \\
\text { intended audience; boldface used for } \\
\text { emphasis. }\end{array}$ & $\begin{array}{l}\text { Most text is easy to read; uses no } \\
\text { more than four different fonts; } \\
\text { amount of text generally fits } \\
\text { intended audience. }\end{array}$ & $\begin{array}{l}\text { Font too small to read easily; more } \\
\text { than four different fonts used; text } \\
\text { amount is excessive for intended } \\
\text { audience. }\end{array}$ \\
\hline Design & $\begin{array}{l}\text { Clean design; high visual appeal; } \\
\text { four or fewer symbol shapes; fits } \\
\text { page without a lot of scrolling; color } \\
\text { used effectively for emphasis. }\end{array}$ & $\begin{array}{l}\text { Design is fairly clean, with a few } \\
\text { exceptions; diagram has visual } \\
\text { appeal; four or fewer symbol } \\
\text { shapes; fits page well; uses color } \\
\text { effectively most of time. }\end{array}$ & $\begin{array}{l}\text { Cluttered design; low in visual } \\
\text { appeal; requires a lot of scrolling to } \\
\text { view entire diagram; choice of } \\
\text { colors lacks visual appeal and } \\
\text { impedes comprehension. }\end{array}$ \\
\hline
\end{tabular}

Figure 1. Rubric for assessing concept map

Scoring system: It consisted of 6 statements, three point categorical score (1-3) were offered for each statement, the total scores ranged from 6 to 18 . So, twelve scores represented average concept map, more than twelve scores considered satisfied concept map while less than twelve considered unsatisfied concept map.

(5) Attitude assessment tool "Likert scale": This was used to assess the nursing students' attitude towards the teaching strategy. The scale adapted from Willis et al. (2010), ${ }^{[13]}$ consists of three levels of response "disagree", "uncertain" or "agree". The scale consists of ten statements. The scoring system was as the follows:

- Positive attitude was considered if grades were more than 20 ,

- Uncertain attitude was considered if grades were 20,

- Negative attitude was considered if grades were less than 20.

The Cronbach Alpha coefficient of the instrument was 0.82 for the Arabic version in Taif University.

\subsection{Pilot study}

A pilot study was carried out on $10 \%$ of the total sample size in order to assess the feasibility of the study, accessibility of the sample and clarity of the tools, as well as to determine the time needed to answer the questions. No modifications were needed on the tools of data collection based on the finding of the pilot study. Students included in the pilot study were not 
excluded from the main study sample because they cannot be excluded from registration to this year.

\subsection{Validity of the tools}

The content validity of the tools were revised by 5 experts in Maternity and Neonatal Health Nursing to test content validity and according to their opinions; no major modifications were carried out in the content.

\subsection{Administrative and ethical considerations}

To carry out the study in the predetermined faculty, letters containing the aim of the study were directed from the researcher to the Dean of the Faculty of Nursing in Fayoum University, as well as the Head of the Department to obtain the permission and help to conduct the study in the faculty. The researcher explained the aim of the study to the students and explained what and why concept mapping is a useful tool for learning and to be aware that this teaching strategy will be used.

\subsection{Fieldwork}

The study was carried out through the three following phases; planning, implementation and evaluation. All those phases nearly 14 months of the academic year 2014/2015. The study started from beginning of July, 2014 till the end of August 2015.

Planning phase: Started by preparing the concept maps for all topics which covered the theoretical part of pregnancy lectures (normal \& abnormal), then handed to experts in the field in order to determine the content validity and clarity of the concept map. Accordingly, modifications were done on the concept map. Lectures as a traditional method of teaching were developed, as well as the teaching materials. In addition, the researcher prepared the pre/post test regarding the concept map. Lectures designed for both groups were delivered according to the following schedule and taught through eight sessions as follows:

Table 1. Lectures of normal and abnormal pregnancy

\begin{tabular}{ll}
\hline Topics & Duration (in hrs.) \\
\hline Physiological and psychological changes in pregnancy & 2 \\
Antenatal care & 2 \\
Diagnosis of pregnancy & 1 \\
Gestational diabetes & 2 \\
Gestational hypertension & 2 \\
Bleeding in early pregnancy & 2 \\
Bleeding in late pregnancy & 2 \\
Cardiac disorder during pregnancy & 2 \\
\hline
\end{tabular}

Implementation phase: The lectures were taught for the control group by traditional method, while the study group was taught the same lectures by concept mapping. Each group was taught the course of pregnancy (normal \& abnormal) throughout 8 consecutive weeks. In the study group, the researcher started to assess students' knowledge about CM using the pre/post test regarding concept mapping. The pretest took 30 minutes to complete done. Before starting the lectures of pregnancy, the study group attended three orientation sessions, to be trained on the concept mapping method and how to construct it. In addition, an illustrated educational booklet prepared by the researcher about constructing concept mapping was offered to the students. After the orientation sessions, a post test about the concept map was held to the study group to ensure their understanding about the concept map. Then, the students in the study group attended the lectures related to pregnancy lectures based on concept map methods. By the end of each lecture, the study group students were asked to construct their own concept maps to represent what they have learned from the lecture. Then, the researcher corrected the students constructed concept maps according to the rubric system. Whenever there were any misconceptions, they were corrected by the researcher and a feedback is given to them before starting the next lecture. The control group was taught by the traditional teaching method.

Evaluation phase: Finally, the mid-term and final exams were used to evaluate students' achievements. By the end of each term, a Likert scale was distributed to the students to assess their attitude regarding the teaching strategy used.

\subsection{Statistical analysis}

Data entry and statistical analysis were done using the Statistical Package for Social Science (SPSS), version 18.0, a statistical software package. Results were presented in frequencies and percentages. Independent-samples $t$-test analysis was used to test statistical significance of some variables and to test effectiveness of the intervention between the two groups. Statistical significance was considered at $p<$ .05 .

\section{RESULTS}

Table 2 represents the demographic characteristics of students in the study and a control group, The table indicates that the mean age of the study and control groups was 19.88 \pm 0.39 and $20.91 \pm 0.50$ respectively. The percentage of students having a technical institute diploma certificate represented $18.5 \%$ in the control group compared to $16.7 \%$ in the study group, while students having secondary school certificate represented $81.5 \%$ in the control group versus $83.3 \%$ in the study group. There were no statistically significant differences between both groups regarding their demographic characteristics. 
Table 2. Demographic characteristics of students in both groups

\begin{tabular}{llll}
\hline \multirow{2}{*}{ Items } & \multicolumn{2}{l}{ Study Group (n= 60) } & \multicolumn{2}{l}{ Control Group (n= 65) } & p-value \\
\cline { 2 - 3 } & No (\%) & No (\%) & .72 \\
\hline Students mean age (in years) \pm SD & $19.88 \pm 0.39$ & $20.91 \pm 0.50$ & .81 \\
Students having technical institute diploma certificate & $10(16.7)$ & $12(18.5)$ & .42 \\
Students having secondary school certificate & $50(83.3)$ & $53(81.5)$ & .92 \\
Gender & & & \\
Male & $19(31.7)$ & $22(33.8)$ & \\
Female & $41(68.3)$ & $43(66.2)$ & \\
\hline
\end{tabular}

Note. (NS) Statistically insignificant at $p>.05$; (HS) Statistically highly significant at $p=.00$.

Table 3 shows the study group means knowledge score regarding concept mapping before and after awareness sessions. It was noticed that the mean score of students' knowledge before the awareness session was $8.9 \pm 4.9$, while after the sessions, it was $30.0 \pm 5.9$. There was a highly statistically significant difference between before and after the awareness sessions regarding students' knowledge about concept mapping.

Regarding the application of concept map scoring rubric for study group assignments, Figure 2 illustrates that more than half $(55.6 \%)$ of the study group had unsatisfied concept map in the 1st assignment; $44.4 \%$ had average concept map; and no one achieved satisfied concept map in the first trial, while, starting from the second assignment, the number of unsatisfied concept map had declined and the number of average and satisfied increased till the 4th assignment. As well in 4th assignment none of the students' concept map was unsatisfied. On the other hand, $68.9 \%$ of the students in the last assignment achieved satisfied concept map.

Concerning the achievement of study and control groups through the theoretical part of pregnancy lectures in midterm and final exam, Table 4 shows that the study group a achieved higher rate in excellent grade in midterm exam (15.4\%) more than the control group (10.7\%), as well, in the final exam ( $27.6 \% \& 12.3 \%$ respectively). On the other hand, the pass grade was higher among the control group in midterm and final exam (38.3\% \& $31.6 \%$ respectively) more than the students in study group ( $24.2 \%$ \& $11.6 \%$ respectively).

Table 5 reveals that there were highly statistically significant differences between both groups (study \& control groups) regarding the mean scores of the achievement test (cognitive levels) in midterm $(60.4 \pm 4.9 \& 49.7 \pm 4.2$ respectively at $p$ $=.01)$, and final exam $(88.2 \pm 3.3 \& 70.6 \pm 0.3$ respectively at $p=.00$ ).

Figure 3 illustrates the attitude of both groups regarding teaching methods used. It shows that $86.7 \%$ of the studies group had a positive attitude regarding concept mapping, while $68.3 \%$ of the control group had positive attitude regarding traditional method. Meanwhile, the control group represented negative attitude regarding to the traditional method more than the study group $(26.7 \%$ \& $8.3 \%$ respectively $)$.

Table 3. Study group mean knowledge score regarding concept map before and after the awareness sessions

\begin{tabular}{|c|c|c|c|c|}
\hline $\begin{array}{l}\text { Students' knowledge } \\
\text { (Before awareness } \\
\text { sessions) } \\
(n=60)\end{array}$ & $\begin{array}{l}\text { Students' } \\
\text { knowledge (After } \\
\text { awareness sessions) } \\
(\mathrm{n}=60)\end{array}$ & $t$ test & $p$ & Sig. \\
\hline $8.9 \pm 4.9$ & $30.0 \pm 5.9$ & -13.1 & .00 & HS \\
\hline
\end{tabular}

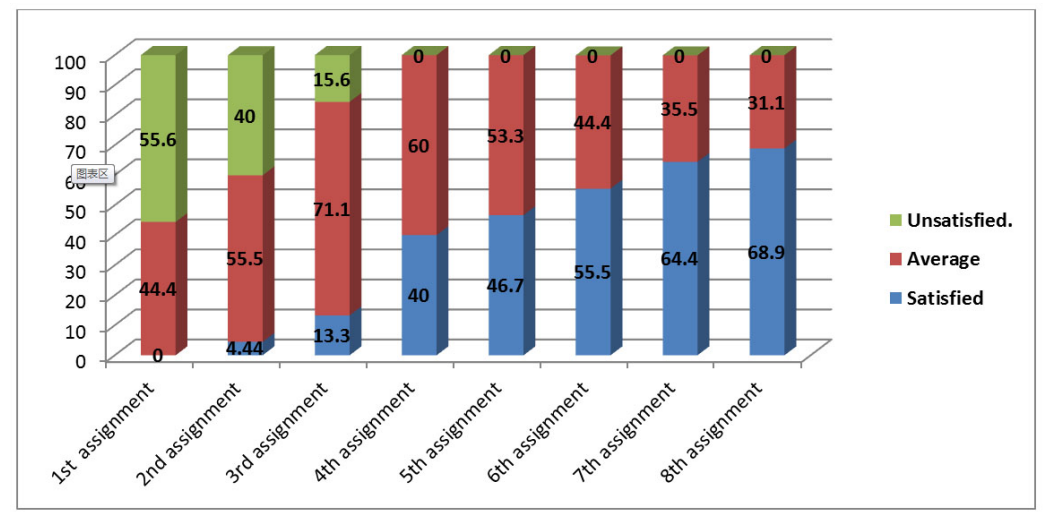

Figure 2. Application of concept map rubric score for the study group assignments $(n=60)$ 
Table 4. Study and control groups' achievement on the theoretical part of pregnancy lectures in midterm and final exam

\begin{tabular}{llllll}
\hline \multirow{2}{*}{ Achievement test } & \multicolumn{2}{l}{ Study group $(\mathbf{n}=\mathbf{6 0})$} & & Control group $(\mathbf{n}=\mathbf{6 5})$ & \\
\cline { 2 - 3 } & Midterm exam & Final exam & & Midterm exam & Final exam \\
\hline Excellent & 15.4 & 27.6 & 10.7 & 12.3 \\
Very good & 29.1 & 25.8 & 12.5 & 15.1 \\
Good & 29.1 & 33.3 & 32.8 & 37.5 \\
Pass & 24.2 & 11.6 & 38.3 & 31.6 \\
Poor & 2.2 & 1.7 & 5.7 & 3.5 \\
\hline
\end{tabular}

Table 5. Comparison of the means score of students' achievement test

\begin{tabular}{|c|c|c|c|c|c|}
\hline \multirow{3}{*}{ Items } & \multicolumn{2}{|l|}{ Group } & \multirow{3}{*}{$t$ test } & \multirow{3}{*}{$p$} & \multirow{3}{*}{ Sig. } \\
\hline & Study group $(n=60)$ & Control group $(n=65)$ & & & \\
\hline & \multicolumn{2}{|l|}{ Mean \pm SD } & & & \\
\hline Midterm exam & $60.4 \pm 4.9$ & $49.7 \pm 4.2$ & 3.06 & .01 & HS \\
\hline \multirow[t]{4}{*}{ Final exam } & $88.2 \pm 3.3$ & $70.6 \pm 0.3$ & 4.11 & .00 & HS \\
\hline & $t=4.70$ & $t=2.80$ & & & \\
\hline & $p=.00$ & $p=.00$ & & & \\
\hline & HS & HS & & & \\
\hline
\end{tabular}

Note. (NS) Statistically insignificant at $p>.05$; (HS) Statistically highly significant at $p=.00$.

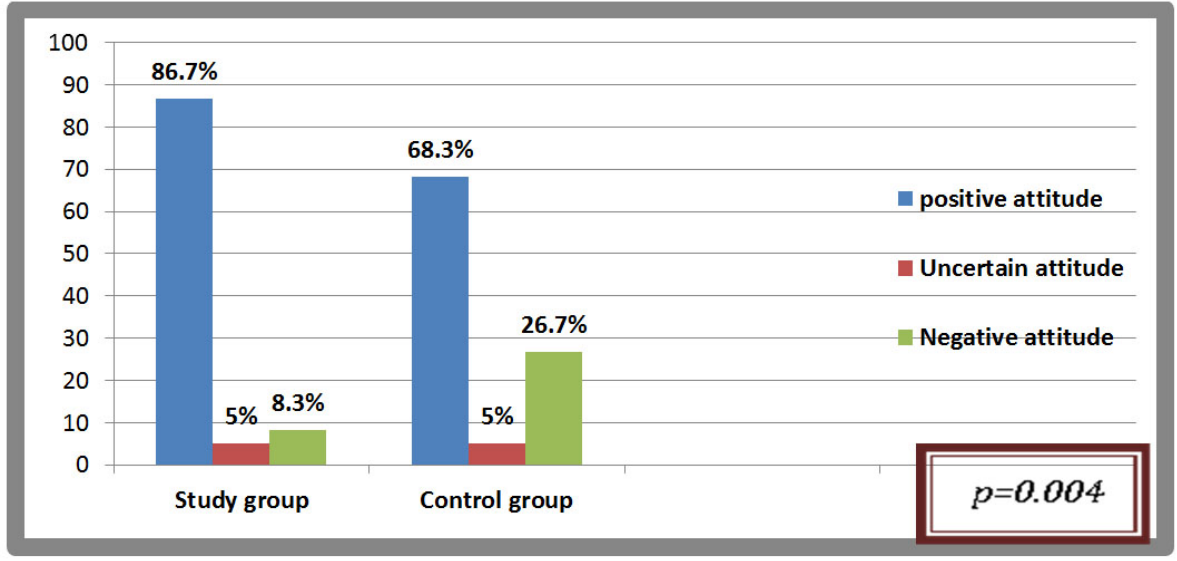

Figure 3. Attitude of both groups regarding teaching methods used

\section{Discussion}

Future graduate nurses will be required to use critical thinking, designing, analyzing and solving various problems as they may face in any situation in the modern performance, where new advanced and sophisticated technologies are to be used. Nurse educators, who are to prepare these future nurses need to use more innovative teaching methods as an alternative of the traditional teacher centered lectures in relation to their patient care, where the student nurses are able and accept to correlate and take rational and objective decisions based on intelligence thinking due to available scientific knowledge (evidence based practice) ${ }^{[14]}$

Linking words on the connecting lines of the concept map and representing concepts in a substantial manner, assist the nurse educator as a teacher to prefer, organize and arrange the relationship between the concepts articulated. For the student nurses, it also facilitates for them to take notes easily without complexity, as well as summarize and synthesize their study subjects. Concept mapping used by nurse educators is one of the modern teaching methods that have the effect of developing and increasing critical thinking also, developing a sense of ownership and empowerment of knowledge. ${ }^{[15]}$

The current study was carried out to evaluate the effect of a concept mapping strategy for improving maternity nursing students' achievement. The study sample consisted of 125 students enrolled in the academic year 2014/2015. In the 
first term, the number of students was 65 and these were subjected to the traditional method of teaching (control group); and in the second term, the number of students was 60 and these were subjected to concept mapping strategy.

Concerning the demographic characteristics of the study sample, the two groups were quite similar, with their sociodemographic data. The results showed that the mean age of the control group was $20.91 \pm 0.50$ years and that of the study group $19.88 \pm 0.39$ years. The percentage of students having secondary school certificate represented the majority in the control and study groups.

The current study results revealed that the mean knowledge score of the study group before the awareness sessions was $8.9 \pm 4.9$ while after the awareness sessions it was $30.0 \pm$ 5.9. There was a highly statistically significant difference between them before and after the awareness sessions $(p<$ .001). This may be due to fact that concept mapping is a new teaching strategy adopted by the researcher in the Faculty of Nursing, Fayoum University, so the students did not have any previous experience regarding this method except after the awareness sessions.

This finding agreed with Eman, ${ }^{[16]}$ who stated that there was a significant difference among the study group before and after the awareness sessions regarding the concept map.

Regarding the application of the rubric score to evaluate the students' concept map assignments in the study group; the present study finding showed that more than half of the sample among study group had not achieved a satisfied score in the 1st assignment, less than half of the sample of the study group had average score, and no one achieved the satisfied concept map in the first trial. Improvement increased from further assignments to another until the last one, where the improvement reached more than two third of the students who achieved a satisfied concept map. This may be explained by the continuous guidance by the researcher and the continuous feedback given by the researcher to the students to improve their assignments (construct the concept map).

The previous finding is in the same line with Daley, ${ }^{[17]}$ who stated that the score of the study group's assignments regarding the concept map rubric was improved from the first to the last assignment.

Concerning the achievement test (cognitive levels) of the students, the present study result indicated that the study group achieved higher grades (excellent \& very good) more than the control group in midterm and final exam of maternity nursing. This could be explained by the fact that exposure to learning through the traditional teaching technique lead to concrete, dualistic thinking and surface learning, while, the concept map strategy improves the ability of the students to organize and manage the knowledge by encouraging students to process information deeply for understanding.

The previous finding was in line with by Chei-Chang, ${ }^{[18]}$ who reported that there was evidence of a positive association between use of the concept map and promoting the students cognitive levels in nursing education. Concept mapping shows concepts in a hierarchical format from general to details, such as a pyramid structure of information in longterm memory. Therefore, concepts learned via this way can remain for a significant long-term and increase learning.

The previous finding was incongruent with van BonMartens, ${ }^{[19]}$ who studied the effectiveness of concept map in a continuing nursing education program and reported that concept map, had no significant impact on their progress of knowledge and practice.

Findings related to the first hypothesis which stated that the concept map teaching method will improve the Maternity nursing students' achievement in the theoretical part of pregnancy lectures over than the traditional method, revealed that concept mapping and traditional methods both could promote the learners' cognitive learning but concept mapping method was more effective than lecture method on students' achievement.

The current study result revealed that there was a highly statistically significant difference between both groups (study $\&$ control groups) regarding the mean scores of the achievement test (cognitive levels) in midterm $(p=.01)$ and final exam $(p=.00)$. The reason for this difference lies in the nature of concept mapping. Since concept mapping is an illustration of students' interpretation about ideas and concepts, it allows students to be aware of mistakes existing in their understanding and leads them to accept the responsibilities of their learning by themselves. Therefore, the concept mapping students have an active role in learning and since the arrangement of concepts in concept mapping is in a hierarchical form, this form is highly similar to the way of arranging information in long-term memory.

This finding agreed with several studies such as those of Gul and Boman, ${ }^{[20]}$ Magnussen, ${ }^{[21]}$ Harrison, and Gibbons. ${ }^{[22]}$ All of these studies confirmed that concept mapping is superior to conventional methods in enhancing students' learning in the cognitive domain. However the current finding is inconsistent with $\mathrm{Hsu},{ }^{[23]}$ who found that although concept mapping had some positive effects on learning, the effect was not statistically significant.

Regarding the attitude of both groups toward the teaching strategies used, the study result revealed that, the majority 
of the students in the study group showed positive attitude toward the concept map strategy more than students in the control group toward the traditional method of teaching. The results also revealed that there was a significant difference among the two groups regarding the students' attitude toward the teaching strategies used $(p=.004)$. This finding may be due that the students in the study group were interested in using the geometric form to organize the lecture's information which helped them to think deeply, and let them feel more motivated.

This result was supported by Shakuntala, ${ }^{[24]}$ and Tseng, ${ }^{[25]}$ who reported that majority of students reported favorable and positive attitude toward $\mathrm{CM}$ and suggested using $\mathrm{CM}$ in non nursing courses.

The previous results are in accordance with those of Rendas $^{[26]}$ and Youssef, ${ }^{[27]}$ who mentioned that there was a significant difference between the study group who was taught by concept map strategy and the control group who was taught by traditional method regarding their attitude towards the teaching methods were used.

However, the previous results are contradicting with those of Allen, ${ }^{[7]}$ who compared the nursing students' attitude who received the lecture course and those who participated in concept map course, and mentioned that there was no statistically significant difference between both groups regarding their attitude toward the teaching method used.

\section{Conclusion}

Based on the findings of the study, the following conclusion could be deduced: The concept mapping method improved the nursing students' achievement (cognitive level) more than the traditional method. Students in the study group had a positive attitude regarding the use of teaching strategy more than those in the control group.

\section{RECOMMENDATIONS}

Based on the study findings, the following recommendations were suggested:

- Utilize the concept map learning strategy in all nursing academic courses (theory \& practice).

- Course planners and educators (faculty staff members) should receive training and acquire skills in adapting $\mathrm{CM}$ as an innovative teaching and learning strategy.

- Further research are still needed for exploring the obstacles hindering the implementation of the concept map method in nursing education, also to study the impact of concept map method on clinical achievement.

\section{CONFlicts OF InTEREST Disclosure}

The authors declare that there is no conflict of interest.

\section{REFERENCES}

[1] Kostovich C, Poradzisz M, Wood K, et al. Learning style preference and student aptitude for concept maps. Journal of Nursing Education 2007; 46(5): 225-231. PMid:17547346

[2] Wilgis M, McConnell J. Concept mapping: An educational strategy to improve graduate nurses' critical thinking skills during a hospital orientation program. The Journal of Continuing Education in Nursing. 2013; 39(3): 119-126. http://dx.doi.org/10.3928/0022012 4-20080301-12

[3] Chen S, Liang T, Lee M, et al. Effects of concept map teaching on students' critical thinking and approach to learning and studying. Journal of Nursing Education. 2013; 50(8): 466-469. PMid:21524017 http://dx.doi.org/10.3928/01484834-20110415-06

[4] Yin YJ, Vanides MA, Ruiz-Primo CC, et al. A comparison of two construct-a-concept-map science assessments: Created linking phrases and selected linking phrases. Journal of Research in Science Teaching. 2012; 42(2): 166-184. http://dx.doi.org/10.1002 /tea. 20049

[5] Ausubel DP, Novak JD, Hanesian H. Educational psychology: A cognitive view (2nd ed.) New York: Holt, Rinehart \& Winston. 1990.

[6] Wang WM, Cheung CF, Lee WB, et al. Self-associated concept mapping for representation, elicitation and inference of knowledge. Nurse Education Today. 2012; 21(1): 52-61.
[7] Allen JD. Effects of concept mapping on meaningful learning and achievement in chemistry. Dissertation Abstracts International. 2012; 50(11): 3542 .

[8] Oliver K. An investigation of concept mapping to improve the reading comprehension of science texts. Journal of Science Education and Technology. 2012; 18(5): 1-18.

[9] Ritch K, Vhang C, Lou S, et al. How concept mapping perception navigates students' knowledge transferred performance. Educational Technology and Science. 2013; 15(1): 102-115.

[10] Arenson J, Drake P. Collabotaive concept mapping and critical thinking and approach to learning and studying. J Nurs. 2011; 50: 466-469.

[11] Pintrich PR, De Groot EV. Motivational and self-regulated learning component of classroom academic performance. Journal of Educational Psychology. 2011; 82(1): 33-40. http://dx.doi.org/10. 1037/0022-0663.82.1.33

[12] McMurray J. Rubric for assessing concept maps. University of Waterloo, California. 2014. Available from: https://uwaterloo. ca/centre-for-teaching-excellence/teaching-resourc es/teaching-tips/assessing-student-work/grading-a nd-feedback/rubric-assessing-concept-maps

[13] Willis GM, Levenson JS, Ward T. Students' attitude toward using concept maps. Meta Cognition and Learning. 2010; 4(2).

[14] Bamidele EF, Oloyede EO. Comparative effectiveness of hierarchical, flowchart and spider concept mapping strategies on students' 
performance in chemistry. World Journal of Education. 2013; 3(1): 66-76.

[15] Nwagbo C, Okonkwo I. Effect of concept mapping teaching strategy on students' achievement in environmental concepts in chemistry. IJSR. 2014; 3(4): 2179-2277.

[16] Eman S. Concept mapping as an innovative teaching strategy to enhance cognitive learning in nursing administration course. 2014.

[17] Daley BJ, Shaw CR, Balistrieri T, et al. Concept maps: A strategy to teach and evaluate critical thinking. Journal of Nursing Education. 2013; 38: 42-47.

[18] Chei-Chang C. The effect of concept mapping on students' learning achievements and interests. Innovations in Education and Teaching International. 2012; 45(4): 375-387.

[19] Van Bon-Martens MJ, van de Goor LA, Holsappel JC, et al. Concept mapping as a promising method to bring practice into science. Public Health. 2014; 128(6): 504-514. PMid:24923995 http: //dx.doi.org/10.1016/j.puhe.2014.04.002

[20] Gul RB, Boman JA. Concept mapping: A strategy for teaching and evaluation in nursing education. Nurse Educ Pract. 2012; 6(4): 199206. PMid:19040878 http://dx.doi.org/10.1016/j.nepr. 20 06.01 .001
[21] Magnussen L. The use of the cognitive behavior survey to assess nursing student learning. J Nurs Educ. 2013; 40(1): 43-6.

[22] Harrison S, Gibbons C. Nursing student perceptions of concept maps: From theory to practice. Nurs Educ Perspect. 2013; 34(6): 395-409. PMid:24475601 http://dx.doi.org/10.5480/10-465

[23] Hsu L, Hsieh SI. Concept maps as an assessment tool in a nursing course. Journal of Health Science. 2015; 2(4): 249-260.

[24] Shakuntala BS, Nirmala T. Attitude of students on concept mapping: An innovative teaching learning strategy. Nitte, University Sudbury, MA: Jones and Bartlett Publishers; 2012.

[25] Tseng KH, Chang CC, Lou SJ, et al. How Concept-mapping Perception Navigates Student. Knowledge Transfer Performance. 2012.

[26] Rendas AB, Fonseca M, Pinto PR. Toward meaningful learning in undergraduate medical education using concept maps in pathophysiology course. Adv Physiol Educ. 2015; 30(1): 23-9. PMid:16481605 http://dx.doi.org/10.1152/advan.00036.2005

[27] Youssef AM, Mansour M. The effect of concept mapping on students' learning achievements and interests in Taif University. Life Science Journal. 2012. 